\title{
Strategic Planning for New Faculty: From What to How
}

\author{
Justin S. Davis \\ Mississippi State University
}

\begin{abstract}
This paper describes methods of implementing advice given to new faculty members. Every new faculty member is (or should be) given advice through mentoring, new faculty training, and development programs. Many times new faculty are told what they need to do to succeed, but not how to do it.
\end{abstract}

\section{Introduction}

Broad advice targets a broad audience, but specific advice is more difficult to give because every faculty member's situation has different priorities. Therefore, the implementation of the broad advice is left to the creativity of the faculty member. For example, faculty members are told to set goals, but they should also be told how to go about choosing correct goals. This paper describes a process for setting specific career goals and building a hierarchy of objectives to complete them. This makes long term goals easier to handle by dividing them into smaller manageable goals (month-to-month).

Since faculty members are only human, state of mind effects productivity. Low morale often leads to low productivity which in turn leads to time inefficiency. Burn-out and low morale are factors that can be accounted for with good goal setting. For example, instead of setting a goal in number of dollars of grant/contract money, set a goal which the faculty member has control over like number of proposals written. Since faculty members have no control over the acceptance of a proposal once submitted, it should not be a defined goal.

Another broad topic of advice is time management. Most faculty members have different inefficiencies in time management due to their personality, so self-analysis is important to discover strengths and weaknesses. This paper describes techniques for selfanalysis and how that analysis can be used to determine which advice is best suited to maximize time efficiency.

This paper is not only for junior faculty on how they can implement good advice, but also for senior faculty disseminating that advice on how they can make its implementation easier. A large amount of advice already exists and should be distributed to new professors ${ }^{1-5}$. 
Most advice contains some or all of these general areas of advice:

- Setting goals

- Writing papers

- Writing proposals

- Getting good teaching evaluations

- Managing graduate students

- Sustaining good mental health

This paper is no different, but it will give specific advice on not only what to do, but how to do it.

\section{Setting goals}

The best approach to setting goals is the divide-and-conquer method. At the top of every goal list for tenure-track professors should be "get promotion and tenure". All other goals should derive from this one and should lead back to this one. Tenure track professors have so little time that any time spent on not getting promotion and tenure is wasted. Therefore the first question a new professor must ask is "What do I need to do to get tenure?"

Most departments don't have a fixed document listing the requirements for P\&T since every professor's situation is unique. General guidelines at the college or university level may exist, but are often very broad. Almost every professor must submit a very lengthy (5-6 years worth of work) promotion and tenure application. This is what the department head or chair reviews before making a recommendation. A P\&T committee may also need to review the application. Therefore, asking the people who will review the application is a good way to understand the requirements, but it isn't the only way.

One solution to creating a good P\&T document is emulation: find someone who recently received tenure and ask to review their application. Logically, if your application looks like this one, then it should also pass. Write a mock P\&T application based on the ones that recently received tenure. This should include expected personal accomplishments, papers written to conferences and journals, classes created or revised, etc. It should look like a P\&T application but tailored for your own conferences and interests. Including a theme helps unify and streamline it which can incorporate a teaching portfolio [8] and service strategy along with a research plan [9]. The final step is to review it with the department head and ask "if my application looked like this, would I get tenure?" If the answer is yes, then that application can be used as a starting point to writing goals. One thing to keep in mind when writing the mock P\&T application is that many departments require external letters of recommendation, so a good P\&T application may not be the only factor in determining P\&T.

The mock P\&T document will list all long term goals (5-6 years) including number of papers written, number of proposals written, etc. From there, an accurate 
predication can be made for the halfway point to tenure which become the medium term goals. From the medium terms goals, yearly goals (short term goals) can be planned. Once the yearly goals are set, then the task of obtaining P\&T becomes much more manageable and even realizable.

With conference submission dates being up to six months early or more, having a month-to-month plan is helpful. From the yearly goals, the month-to-month goals can be easy to write. If the goals include submitting to three specific conferences, then the submission deadlines should be included in that month's goal list. Since the background material and research must be completed before then, the previous month's goals write themselves.

One thing to note in a P\&T application is the number of dollars received from grants and contracts. However, that should not be included when writing goals. Professors have little control over the number of dollars they receive. Even with a perfect proposal, luck has a large influence on receiving any money. For example, the National Science Foundation grants roughly $10 \%$ of all proposals for engineers. Therefore, instead of writing a goal in number of dollars received, write a goal in number of proposals submitted. This helps keep a high morale because it is something that can be achieved without letting luck factor into the equation.

Another key to keeping a high morale is to keep updating the goals sheets. Anytime a goal is accomplished, the goal sheet should be updated to indicate what happened and when it was completed. Looking back on the completed goals helps boost morale and shows progress being made towards the overall goal: promotion and tenure. For an even better morale boost, the completed goals can be shown to the department head to make sure he/she knows about the good progress.

One thing to keep in mind with any set of goals is that goals can change. Sometimes a goal isn't possible or an unforeseen event occurs. Sometimes goals aren't possible to set a date for. Sometimes unexpected things will happen that had no set goal. For example, awards are very hard to set goals for because it's hard to do anything specific to receive them.

\section{Time Management}

Poor time management is one of the fundamentals of failure [10]. The key piece of advice for time management is to only do activities which help attain promotion and tenure. Otherwise your time efficiency decreases. However, this piece of advice is only an ideal because of practical matters. For example, if a professor is going out of town and asks you to fill in for a lecture, saying yes will not help directly get P\&T. However, it may be appropriate for a number of personal reasons or just to be a team player. You can at least agree to have him/her teach one of your lectures in exchange. On the other hand, saying yes to everyone's needs leads to doing too many favors and not getting goals completed. 
The best approach is to realize your type of personal trends and alter your routines to maximize time in the right way. For example, person $\mathrm{X}$ has a problem saying no. Person $\mathrm{X}$ always is a minority female professor who everyone wants on their committee. She keeps saying yes to everyone and before long she has filled up her days with committee meetings. In the end, she will have a long list of committees she served on, but will have lost so much time that she missed a deadline to submit a conference paper or proposal. Person X has become "time poor" where she has made so many commitments, she has no time left to commit to developing her own research program. This derived from the phrase "house poor" in real estate when someone spends too much money on a house, and then has no money left over after the mortgage payment each month. They may be making an excellent salary, but all their money is tied up in monthly payments.

On the other hand, person $\mathrm{Y}$ has no problem saying no. As a matter of fact, he will say no to everyone who asks a favor of him. After some time, he gets a reputation as someone who is not willing to cooperate or work collaboratively. In the end, he misses some opportunities that weren't apparent at first because of his lack of networking. Perhaps he could have played a small part in a research topic and gotten included as an author on a paper. Instead he will now need to write an entire conference paper on his own.

The key to good time management is finding which personality type is best suited to you, and follow the correct advice: person X needs to learn to say no, person Y needs to learn to say yes. These types of trends are very apparent in many new professors. If in doubt, see how an opportunity fits with your goals or your P\&T theme.

\title{
4. Teaching
}

Every university has a different stance on teaching requirements for promotion and tenure. The promotion and tenure guidelines at Mississippi State University say,

\begin{abstract}
"An assistant professor is a faculty member with a doctoral degree (or appropriate experience) in the discipline, who possesses potential for successful performance in teaching, research and service in a university environment. For tenure, the faculty member must exhibit excellent performance in one of the three areas and satisfactory performance in the other two."
\end{abstract}

However, there is an implication that the excellent performance must be in research. A survey of 506 faculty members from seven universities found that $86 \%$ agreed that research was more important in P\&T than teaching or service [6]. Satisfactory in teaching is often measured by the number of classes or students taught with some regard to student evaluations. Because of this, it is not considered as essential as research for an assistant professor. However, teaching is not an area to neglect. Boice discusses how successful professors spend quality time in teaching and not quantity time [5]. Since a 
certain amount of time is required for teaching, it is best to plan to use that time to its maximum effectiveness.

The first advice for teaching classes is to try and teach the same class(es) over and over every semester. This may become boring, but the time investment required to teach a class for the first time is much higher than the second or third. Adopt one class and hold on to it. The quantity of different classes is not important on a P\&T document, but the number of students who passed through the class may be.

As long as the same classes are being taught over and over, collect data along the way which can be used in an education paper. Watch trends and try experiments in the class material. As long as so much time is spent with teaching, it is worthwhile to try and get a paper or two out of it. At some point revise the course material or, if the class has a lab associated with it, revise the lab portion. While the professor must be aware of meeting ABET accreditation requirements, there are guides to make this process easier [7]. This can be a significant addition to a P\&T document and will show an enthusiasm for teaching.

Selecting the correct class to teach is critical (if it is an option). Senior-level classes average competency level is higher than freshman or sophomore level classes. This makes the class easier to teach and easier to handle. Typically, maturity levels are higher which leads to fewer headaches. Also, the students will be considering postgraduation options. If they are considering graduate school, the brightest students are in an excellent place to be recruited into your research program. Some senior-level classes are split-level, so early graduate students are also in the class. This means they may not have an advisor yet, so they are also in a good place to be evaluated for an invitation into your research program. Use the classroom as an evaluation of competency for potential researchers.

Create a new graduate level or split-level course. This can also be a significant addition to a P\&T document and is better than teaching an unrelated undergraduate class. It may not be a good idea in the first year because of the amount of time involved in starting a new course from scratch, but perhaps for the second year. The best design for a new class would be to set a course goal of getting a research paper or two from simple projects or experiments that the students can perform. The point of creating a new a class is to help your research in some way since that is the main focus of P\&T.

Along with the classes, it is a good idea to pick an education conference to attend every year (for example, an American Society for Engineering Education conference). They all give good advice for new educators. As long as you are attending the conference, write a paper for it. For example, experiment with a new in-class project one semester and write about it. And as long as you are submitting one paper, submit multiple papers to really justify spending money to go to an education conference. 


\section{Research}

The main focus of most P\&T is research. Every professor's research is very different which makes giving advice difficult. But looking at the themes in the P\&T requirements tends to similar advice. For example, most P\&T documents require professors to be building a national reputation. However, how that is accomplished and measured is not very well defined.

The best source of national reputation is at conferences. So the best route is to pick a prestigious research-related conference or two and attend every year. The depth of popularity comes from seeing the same people every year at the same conferences. In addition to the regular conference(s), attend one different conference each year to expand the breadth of your popularity.

A side-effect of becoming well known is being invited onto conference committees, panels, chairs, etc. This falls under the service part of the P\&T document, but should be more useful for gaining national reputation. The drawback to committing to an office or chair is that you must attend the conference. This is why planning on attending the same conference every year is a good idea. Again, since attendance is mandatory, try and get a paper accepted (or two). Conferences take a great deal of time (including travel) so get the most out of them. A secondary side effect to national reputation is that it becomes easier to get papers accepted at places where you have been accepted before. This may be a questionably unethical occurrence, but that is outside the focus of this paper.

Some conferences also have travel grants associated with them for new faculty members. This helps alleviate early funding problems. However, if funding becomes a problem, overhead may be available from the department until grant and contract money starts arriving.

Many funding resources are available for new faculty which can help kick-start your research program. Research Initiation grants are common within academia through universities, conferences, and societies. Often the funding rate is much higher on these than from the standard funding agencies, although the dollar amount is usually fixed and is much lower. The length of the written proposal is also shorter, enabling many more to be written within the same time. Early in a new professor's career, quantity of grants is more important than the dollar amount on them. Once you get tenure, then the dollar amounts are expected to go up.

\section{Advertise}

A part of a new professor's success is networking. Successful professors should spend 3-5 hours each week networking [5]. Conference papers are often regarded as an excellent source of advertising work. However, a significant amount of time is devoted to attending a conference and giving presentations. Journal papers and magazine articles 
are also excellent sources of advertising, but are more passive and may not lead to as much collaboration.

When a new professor first steps onto campus, very few people know his/her name, let alone his/her research topic and specializations. Within the university, the best way to increase the number of collaborations is to get people to know who you are. This can be done in many ways, both passively and actively.

Passive ads are an excellent way to increase the awareness of a new professor. If possible, display posters or papers on bulletin boards around the department or college. Whenever someone passes an attractive poster, they may stop to read it and learn more about your research topics. When students are waiting outside classrooms, they may spend a few minutes learning who you are. Web pages are also good ways to raise awareness, and they extend outside the university. If someone reads a magazine article, they may want to find out more about you, and the first place they will go is to the web.

Active advertisement is more time consuming, but usually leads to more collaboration. This means being visible around campus. Give presentations and seminars to the student professional societies. Have lunch with other professors. It is by far a better use of your time than eating at your desk. Often university affairs and the informal news around campus is discussed. This information may otherwise be very difficult to discover.

\section{Students}

Many people differ in the number of students each professor finds satisfactory to include in a research program. One doctoral student, one masters student, and one undergraduate is a good balance for an assistant professor. Each degree has a different maturity and skill level. The doctoral student will be most helpful in research and should be the most efficient worker. The masters student is a little more speculative, but can perform more "grunt-work" in the lab. The undergraduate student should be a very high quality student who may attend graduate school. Often, the longer a student has been in a research program, the more helpful he/she is. Getting someone involved as an undergraduate can create a very efficient doctoral student further down the road.

Students can also be a drain on time, so wait a semester before choosing a doctoral or undergraduate student. The first semester for any new faculty is relatively less productive, and including more students into it can make it worse. Since new graduate students require more time than experienced ones, it may easier to delay accepting any new students. 


\section{Mentors}

Often a mentor is assigned when you arrive on campus. However, multiple informal mentors may provide more useful if chosen correctly. One mentor at each level may be most helpful: Assistant (close to tenure), Associate, and an experienced Full Professor. Each mentor is in a unique situation. The Assistant professor can give insight about going through the tenure process. The Full professor would be helpful in targeting large proposals and finding helpful collaborations. The key to making use of a good mentor is seeking out advice and asking questions. A walk to the mentor's office can save many hours discovering through trial-and-error.

\section{Lifestyle}

One final note about goals, which should be included in any new faculty paper, is that these are only work goals. They should not also be personal goals and dictate lifestyle. Being a new faculty member is very time intensive, but a balance must be formed between work and personal life to ensure good mental health [11]. Have other interests and get involved with those. Getting tenure should not be done at the sacrifice of more important things. Don't trade tenure for a family, because that would be a net gain of zero (or worse). Everyone must choose priorities in life, and work should not be the first on the list.

\section{Conclusion}

In summary, new faculty members are given a great deal of advice, but implementing that advice is where most of the difficulty lies. This paper has outlined a number of methods for setting goals, managing time, planning teaching and research responsibilities, handling students, and getting mentors. While this paper is not an exhaustive list, it provides recommendations on how to take good advice and implement it.

\footnotetext{
Resources

${ }^{1}$ McKeachie W.J., Teaching Tips: Strategies, Research, and Theory for College and University Teachers, 10th Edition, Houghton Mifflin Company, Boston, MA, 1999.

${ }^{2}$ Reis R. M., Tomorrow's Professor: Preparing for Academic Careers in Science and Engineering, IEEE Press, 1997.

${ }^{3}$ Solti J., et. al, "Getting from Here to There" A Self-Diagnostic for Stimulating Faculty Development", Proceedings of the 1999 Annual American Society for Engineering Education Conference, Session 1675.

${ }^{4}$ Felder R.M., Brent R., "Faculty Development: Getting the Sermon Beyond the Choir", Proceedings of the 1998 Annual American Society for Engineering Education Conference, Session 1213.

${ }^{5}$ Boice, R., The New Faculty Member, San Francisco, Jossey-Bass, 1992.

${ }^{6}$ Lee, J., D.M. Castella, and S.G. Middleton, "Faculty Perception of Academe's Evaluation System," Journal of Engineering Education, 86(3), 1997, pp. 263-267.

${ }^{7}$ Felder R.M., Brent R., "Designing and Teaching Courses to Satisfy ABET Engineering Criteria", Journal of Engineering Education, 92(1), 2003, pp. 7-25.
} 
${ }^{8}$ Lozano-Nieto, A.., "Developing and Articulating Your Teaching Philosophy", Proceedings of the 2004 American Society for Engineering Education Annual Conference \& Exposition, Session 1175.

${ }^{9}$ Bruce, L.M., Bruce, J.W., "Maximizing Your Productivity as a Junior Faculty Member:

Balancing Research, Teaching, and Service," Proceedings of the 2004 American Society for Engineering Education Annual Conference \& Exposition, Session 1475.

${ }^{10}$ R. M. Reis, Tomorrow's Professor: Preparing for Academic Careers in Science and Engineering, IEEE Press, 1997.

${ }^{11}$ Lima, M., "Tips for beginning faculty in engineering", Proceedings of the 2004 American Society for Engineering Education Annual Conference \& Exposition, Session 1475.

Biographical Information

\section{JUSTIN STANFORD DAVIS}

Justin Davis received his Ph.D. in Electrical Engineering from the Georgia Institute of Technology in August 2003, as well as his M.S. and B.E.E. degrees in 1999 and 1997. His research interests include digital testing for high-speed systems, SoCs, and SoPs. He is currently an Assistant Professor in the Department of Electrical Engineering at Mississippi State University. 